\title{
Effect of inorganic carbonate and organic matter in thermal treatment of mercury-contaminated soil
}

\author{
Kanghee $\mathrm{Cho}^{1} \cdot$ Jinkyu Kang ${ }^{1} \cdot$ Songbae Kim ${ }^{1} \cdot$ Oyunbileg Purev ${ }^{2} \cdot$ Eunji Myung ${ }^{2} \cdot$ Hyunsoo Kim $^{2} \cdot$ Nagchoul Choi $^{1}$
}

Received: 24 February 2021 / Accepted: 16 April 2021 / Published online: 26 April 2021

(C) The Author(s) 2021

\begin{abstract}
Thermal treatment of mercury ( $\mathrm{Hg}$ )-contaminated soil was studied to investigate the desorption behavior of $\mathrm{Hg}$ at different temperatures. The soil samples were collected from two locations with different land uses around the mine and industrial site. The effect of soil properties such as inorganic carbonate minerals and organic matter content on $\mathrm{Hg}$ desorption was investigated to understand the thermal desorption process. The effect of soil composition on $\mathrm{Hg}$ desorption showed that behavior at $100^{\circ} \mathrm{C}$ was similar, but a different behavior could be found at $300^{\circ} \mathrm{C}$. The thermal desorption efficiency at $300{ }^{\circ} \mathrm{C}$ is affected by the thermal properties of soils and the $\mathrm{Hg}$ desorption capacity of the soils. The $\mathrm{Hg}$ from both soil types was removed above $300{ }^{\circ} \mathrm{C}$, and $\mathrm{Hg}$ was effectively removed from mine soil due to the partial decomposition of carbonate in the soil composition, while industrial soil showed that desorption would be restrained by $\mathrm{Hg}$ organic matter complexes due to organic matter content. Despite a relatively higher concentration of $\mathrm{Hg}$ in the mine soil, $\mathrm{Hg}$ removal efficiency was greater than that in the industrial soil. Sequential extraction results showed that only the $\mathrm{Hg}$ fractions (residual fractions, step 6) in mine soil changed, while the industrial soil was affected by changes in $\mathrm{Hg}$ fractions (step 3 to step 6) at $300{ }^{\circ} \mathrm{C}$. Changes in soil $\mathrm{pH}$ during thermal desorption are also influenced by heating time and temperature. Therefore, the mechanisms of $\mathrm{Hg}$ desorption during thermal treatment were observed by soil properties. The volatilization of $\mathrm{Hg}$ in the soil is induced by organic carbon, while soil $\mathrm{Hg}$ release is controlled by organic matter complexes.
\end{abstract}

Keywords Mercury $\cdot$ Inorganic carbonate $\cdot$ Thermal treatment $\cdot$ Desorption $\cdot$ Temperature

\section{Introduction}

Mercury $(\mathrm{Hg})$ contamination has become an environmental problem and attracted increasing attention (O'Connor et al. 2019; Wang et al. 2019). Sites contaminated with $\mathrm{Hg}$ are widespread due to human activities such as mining and coal combustion, leading to soil contamination. Almost all $\mathrm{Hg}$ compounds are toxic and can be dangerous at very low levels in the environment. Exposure to $\mathrm{Hg}$ has been reported to cause diseases (Feng and Qiu 2008). Hg-contaminated soil is considered a hazard due to the toxic characteristics of $\mathrm{Hg}$ and the

Responsible Editor: Philipp Gariguess

Nagchoul Choi

nagchoul@snu.ac.kr

1 Research Institute of Agriculture and Life Sciences, Seoul National University, Seoul 08826, Korea

2 Department of Energy and Resource Engineering, Chosun University, Gwangju 61452, Korea fact that it can be readily taken up by agricultural crops ( $\mathrm{Li}$ et al. 2019). When $\mathrm{Hg}$ gets into a food chain, it damages the nervous systems and reproductive systems of mammals, including humans. Because $\mathrm{Hg}$ is a persistent substance, it can build up. Hence, $\mathrm{Hg}$ can accumulate in the human body through the food chain, and this could be an even more serious problem in the future (Zhao et al. 2019).

In contaminated soils, soil components play important roles in regulating contaminant retention, which influences the mobility, solubility, and toxicity of contaminants in the soil. Among the soil components, $\mathrm{O}, \mathrm{N}$, and $\mathrm{S}$, which contain functional groups of organic ligands involved in the soil organic matter, are considered important in immobilizing contaminants due to their stable complex formation (Vasques et al. 2020). In the soil, $\mathrm{Hg}$ is mostly bound to mineral surfaces and organic matter. Overall, the various forms of $\mathrm{Hg}$ species including $\mathrm{HgCl}_{2}, \mathrm{HgS}$, and $\mathrm{HgO}$ are affected by the organic matter in soil (Wang et al. 2012; Park et al. 2015), especially high molecular weight hydrophobic compounds or hydrophobic neutral organic matter (Stevenson 1994; Li et al. 2019). 
According to the hard and soft acids and bases (HSAB) principle, $\mathrm{Hg}$ retention in soil is controlled by organic matter functional groups, which thereby play an important role in soil-Hg binding (Riccardi et al. 2013; Reis et al. 2016). Because of the interactions between $\mathrm{Hg}$ and soil components, $\mathrm{Hg}$ can bind more strongly with soil constituents than many other metals in soil (Tomiyasu et al. 2017). Unfortunately, Hg-contaminated soils, owing to their different characteristics, have caused substantial challenges in soil remediation. Therefore, the soil in the Hg-contaminated sites must be treated by appropriate remediation techniques to prevent contamination problems.

Contaminated soils have traditionally been treated with remedial techniques (Jho et al. 2015; Huang et al. 2019; Cho et al. 2020), such as soil washing, solidification/stabilization, thermal desorption, and phytoremediation, which aim to remove contaminants from soil to achieve target cleanup thresholds. Among them, many researchers have reported the feasibility of $\mathrm{Hg}$ remediation with thermal treatment (Rumayor et al. 2013; Reis et al. 2015). Generally, thermal treatment can be considerably influenced by soil properties. To increase the heat mass transfer efficiency, there is a need to consider thermodynamic $\mathrm{Hg}$ speciation and $\mathrm{Hg}$ transfer between the solid and gas phases. The saturated vapor pressure of soil minerals with increasing temperature is likely to affect thermal desorption, which is related to thermal vaporization and desorption kinetics. During the thermal treatment, the increased vapor pressures from soil compositions can destroy the force existing between soil and $\mathrm{Hg}$, which improves the thermal transfer capability, facilitating $\mathrm{Hg}$ desorption, vaporization, and removal by induced gas flow (Falciglia et al. 2011; O'Brien et al. 2018). However, Hg sorption onto the soil matrix can occur as nonspecific or specific adsorption, forming inner-sphere complexes, such as specific adsorption, hindering $\mathrm{Hg}$ desorption with increasing temperature. Because of such binding, soil minerals, and the amount and type of organic matter in the soil can significantly affect the transition from the soil to the gas phase of $\mathrm{Hg}$. Therefore, thermal desorption is controlled by soil properties and multiple desorption mechanisms such as film diffusion, chemical desorption, and intra-particle diffusion (Li et al. 2020).

Several parameters have been associated with the efficiency of the thermal desorption for soil contaminated with $\mathrm{Hg}$, in terms of temperature, heating rate, reaction time, and chemical additives (Guo et al. 2017; Lee et al. 2017; Liu et al. 2019; Tian et al. 2019). In the literature, there is no unique practice for thermal desorption. In recent years, most studies have investigated the thermal treatment removal efficiency of $\mathrm{Hg}$ at various temperatures and focused on how to decrease the temperature when thermal treatment with additives such as $\mathrm{FeCl}_{3}$ and $\mathrm{SnCl}_{2}$ was applied (Ma et al. 2014; Lee et al. 2020). However, thermal treatment with additives is likely to affect soil properties that are related to soil qualities because a large amount of additive is still required, and post-treatments are still necessary. In addition, the additive remains in the soil for a long time. Additionally, many studies principally analyzed the effects of initial soil conditions on thermal desorption efficiency with $\mathrm{N}_{2}$ gas flow, but little attention has been paid to the effects of change of soil properties during thermal desorption process. In this study, we investigated the remediation of two soils contaminated by $\mathrm{Hg}$ using thermal treatment under air, and the objectives of this study were to evaluate the influence of soil composition on $\mathrm{Hg}$ removal and to investigate the behavior of $\mathrm{Hg}$ at different temperatures. Changes in soil properties during thermal treatment were also investigated by heating time and temperature.

\section{Materials and methods}

\section{Hg-contaminated soil}

Soil samples were collected from each of the two locations with different land uses around the mine and industrial site of Guizhou province, China. The soil samples were air-dried and passed through a 2-mm sieve. To investigate the chemical composition of the soils, atomic-absorption spectrophotometry (AAS, AA-7000, Shimadzu, Japan) and X-ray fluorescence (XRF, S4 PIONEER, Bruker AXS, Germany) were performed. The total concentrations of $\mathrm{Hg}$ in $1-\mathrm{g}$ soil samples were extracted using $\mathrm{HCl}$ and $\mathrm{HNO}_{3}$ at a 3:1 ratio (i.e., aqua regia).

A six-step sequential extraction proposed by Hall and Pelchat (2005) was conducted for $\mathrm{Hg}$ extraction from contaminated soils, which included soluble and exchangeable (step 1), labile organic components (step 2), amorphous oxidebound (step 3), crystalline oxide-bound (step 4), non-labile organic and elemental (step 5), and sulfide-bound and residual (step 6) fractions. A detailed description of the sequential extraction procedure used in this study is summarized in Table S1.

\section{Thermal treatment of Hg-contaminated soil}

A series of 10-g samples were taken in a pre-weighed quartz boat, pyrolyzed in an electric furnace under an air atmosphere at different temperatures. A heating rate of $10{ }^{\circ} \mathrm{C} / \mathrm{min}$ was performed in an electric furnace to reach the specific temperature and residence times. Once the electric furnace reached the expected temperature from 100 to $700{ }^{\circ} \mathrm{C}$, the sample was inserted into an electric furnace for $30 \mathrm{~min}$. After the experiment, the contents were cooled to ambient temperature. To investigate the effect of soil properties, $\mathrm{Hg}$ sequential extraction of the thermally treated soils was conducted. After each sequential extraction step, the solid residues were recovered, and the residues were examined comparatively with bulk soils via X-ray diffraction (XRD, X'Pert Pro MRD, Panalytical, 
The Netherlands) and Fourier transform infrared (FTIR) spectroscopy (Nicolet 6700, Thermo Fisher Scientific, USA). Moreover, extraction of water-soluble organic matter was conducted in order to describe the decomposition of the organic matter. The total organic carbon (TOC) of soil organic matter in soil was extracted by adding $15 \mathrm{~mL}$ of water to $2.0 \mathrm{~g}$ of soil in a $50-\mathrm{mL}$ conical tube. TOC content was measured using a TOC analyzer (TOC-V SCN, Shimadzu, Japan) without further dilution. Hg removal efficiency was calculated according to the following expression:

$R(\%)=\frac{C_{0}-C}{C_{0}} \times 100$

where $C_{0}$ is the initial contaminant concentration in soil $(\mathrm{mg} / \mathrm{kg})$ and $C$ is the residual contaminant concentration in soil after the thermal treatment $(\mathrm{mg} / \mathrm{kg})$.

\section{Kinetic experiments of $\mathrm{Hg}$-contaminated soil}

The $\mathrm{Hg}$ removal kinetics of the two soil samples were also investigated at 100 and $300{ }^{\circ} \mathrm{C}$ for different times in the range of 10-60 min. Experiments were performed in duplicate; for each selected temperature, weight and $\mathrm{pH}$ difference were compared according to the pyrolytic conditions. An exponential decay kinetic model (Falciglia et al. 2011) was applied to evaluate the experimental data. The kinetic equation can be expressed by Eq. (2) as follows:

$C_{t}=C_{0} e^{-K t^{n}}$

where $C_{t}$ is $\mathrm{Hg}$ concentration in soil $(\mathrm{mg} / \mathrm{kg})$ after a treatment time $t$ ( $\mathrm{min}), C_{0}$ is the initial $\mathrm{Hg}$ concentration in soil $(\mathrm{mg} / \mathrm{kg})$, $K\left(\mathrm{~min}^{-1}\right)$ is the rate of decay of the function, and $n$ is a parameter that represents the non-linearity of thermal desorption kinetics.

\section{Characterizations}

The thermo-gravimetric behavior of the sample was analyzed with a thermo-gravimetric analyzer (TGA, SDT Q600, TA Instruments, USA) in an air environment. The thermogravimetric behavior of the sample was analyzed at a heating rate of $10^{\circ} \mathrm{C} / \mathrm{min}$ under air, and the scan range was approximately $900{ }^{\circ} \mathrm{C}$. Particle size analysis was conducted using a laser particle size analyzer (Mastersizer 2000, Malvern, UK). The $\mathrm{pH}$ of the samples was analyzed by mixing with deionized water at a ratio of 1:5 (soil:deionized water) using a $\mathrm{pH}$ meter (D-71, Horiba, Japan). The organic carbon, nitrogen, and sulfur contents were analyzed using an elemental analyzer (VarioEL, Elementar, Germany). The organic matter content was determined using the ignition method (Heiri et al. 2001). In this test, $5 \mathrm{~g}$ of the soil sample was heated for $1 \mathrm{~h}$ at $400{ }^{\circ} \mathrm{C}$, and the weight loss was determined and assumed to represent the organic matter content in the soil. The samples were subjected to XRD analysis. $\mathrm{Cu} \mathrm{K} \alpha$ radiation was used at an acceleration voltage of $40 \mathrm{kV}$ and a current of $30 \mathrm{~mA}$. The $2 \theta$ section from 10 to $70^{\circ}$ was analyzed for the soil. The functional groups of samples were characterized using a Fourier transform infrared spectrometer. To reveal the elemental composition of soils used in the present study, both soil types were analyzed by field emission scanning electron microscopy (FESEM, S4800, Hitachi, Japan) with an energy dispersive spectrometer (EDS).

\section{Results}

\section{Characterization of Hg-contaminated soil}

The physicochemical characterization of the soil samples is summarized in Table 1, and the mine and industrial soils show different chemical compositions. The organic matter in the mine and industrial soils was $1.90 \%$ and $8.60 \%$, respectively. Higher organic carbon content was observed in the mine soil. Both study soils were primarily contaminated with $\mathrm{Hg}$. The concentration of $\mathrm{Hg}$ in each sample was $1049.2 \pm 15.3$ (mine soil) and $38.3 \pm 2.18$ (industrial soil) $\mathrm{mg} / \mathrm{kg}$, respectively. The minerals found by the XRD analysis of mine soil were calcite, dolomite, and quartz, while muscovite and quartz were observed as the major minerals in the industrial soil. In addition, the main chemical compositions of the mine soil are dolomite and quartz, in which $\mathrm{SiO}_{2}, \mathrm{CaO}$, and $\mathrm{MgO}$ are dominant, while the industrial soil is primarily associated with $\mathrm{SiO}_{2}, \mathrm{Al}_{2} \mathrm{O}_{3}$, and $\mathrm{Fe}_{2} \mathrm{O}_{3}$. The $\mathrm{pH}$ of mine soil was higher than that of

Table 1 Physicochemical properties of soil samples

\begin{tabular}{|c|c|c|}
\hline Parameters & Mine soil & Industrial soil \\
\hline $\mathrm{pH}$ & 7.46 & 6.55 \\
\hline Organic matter $(\%)$ & 1.90 & 8.60 \\
\hline Sand $(\%)$ & 26.7 & 16.0 \\
\hline Silt (\%) & 71.3 & 81.8 \\
\hline Clay (\%) & 2.0 & 2.2 \\
\hline Organic C (\%) & 9.21 & 1.04 \\
\hline $\mathrm{N}(\%)$ & 0.13 & 0.16 \\
\hline $\mathrm{S}(\%)$ & 0.15 & 0.47 \\
\hline $\mathrm{Hg}(\mathrm{mg} / \mathrm{kg})$ & 1049.2 & 38.3 \\
\hline $\mathrm{SiO}_{2}(\mathrm{wt} \%)$ & 36.9 & 54.0 \\
\hline $\mathrm{CaO}(\mathrm{wt} \%)$ & 33.4 & 0.42 \\
\hline $\mathrm{MgO}(\mathrm{wt} \%)$ & 15.8 & 1.17 \\
\hline $\mathrm{Al}_{2} \mathrm{O}_{3}(\mathrm{wt} \%)$ & 7.71 & 26.9 \\
\hline $\mathrm{Fe}_{2} \mathrm{O}_{3}(\mathrm{wt} \%)$ & 3.51 & 13.3 \\
\hline $\mathrm{SO}_{3}(\mathrm{wt} \%)$ & 0.19 & 0.10 \\
\hline
\end{tabular}


industrial soil, which could be because of carbonate minerals such as dolomite and calcite. The elemental distribution of the soil particles was explored by SEM-EDS (Fig. $\mathrm{S} 1$ ), and $\mathrm{Hg}$ was visible in back-scattered electron (BSE) images as a white halo on light gray particles. The SEM images of both soils show that the $\mathrm{Hg}$ has been adsorbed to the mineral surfaces. The EDS elemental spectra analysis showed that the industrial soil was composed of $\mathrm{Al}, \mathrm{Si}$, and $\mathrm{O}$, while the mine soil was composed of $\mathrm{C}, \mathrm{Ca}, \mathrm{Mg}, \mathrm{Si}$, and $\mathrm{O}$. It can be seen that $\mathrm{Hg}$ is mainly incorporated into the carbonate and silicate matrix.

The TG and DSC curves of the soil at a heating rate of 10 ${ }^{\circ} \mathrm{C} / \mathrm{min}$ in air are shown in Fig. 1a-b. In the mine soil, a stage of sharp mass loss between 600 and $750{ }^{\circ} \mathrm{C}$ was found in the high-temperature region. This peak is approximately $26.5 \%$ of the mass loss. This endothermic peak is related to the thermal decomposition of dolomite. The breakdown of dolomite in air could be from 650 to $700{ }^{\circ} \mathrm{C}$ (Qian et al. 2019), and the products of dolomite thermal decomposition are calcite $(\mathrm{CaO})$ and periclase $(\mathrm{MgO})$. Then, calcite decomposition occurs subsequently at a higher temperature (Valverde et al. 2015). The decomposition process of dolomite can be expressed as Reactions 3 and 4.

$$
\begin{aligned}
& \mathrm{CaMg}\left(\mathrm{CO}_{3}\right)_{2} \rightarrow \mathrm{CaCO}_{3}+\mathrm{MgO}+\mathrm{CO}_{2} \\
& \mathrm{CaCO}_{3} \rightarrow \mathrm{CaO}+\mathrm{CO}_{2}
\end{aligned}
$$

The XRD intensity of the dolomite peak was also observed to decrease (Fig. 4a). Contrarily, four major weight losses were found in the industrial soil. These are caused by water volatilizing, humic substances cracking, and the various forms of $\mathrm{Hg}$ species (Soucémarianadin et al. 2019; Li et al. 2020). This suggests that the $\mathrm{Hg}$ in the soil may have been sorbed to the matrix mineral surfaces, or to organic matter. However, the precise species could not be distinguished. In this soil, it was revealed that the organic matter content was relatively high (Table 1). Therefore, $\mathrm{Hg}$ would likely be associated with organic matter complexes in the industrial soil.

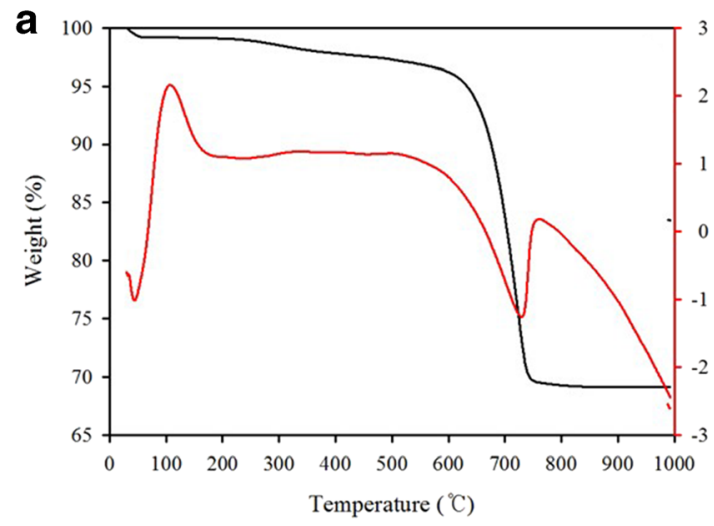

Fig. 1 TG and DSC curves of a mine soil and $\mathbf{b}$ industrial soil

\section{Hg desorption efficiency at various temperatures}

The Hg desorption efficiency for both soils is shown in Fig. 2a and shows the behavior of $\mathrm{Hg}$ at different temperatures. The soil $\mathrm{Hg}$ desorption began to increase with increasing temperature, and $\mathrm{Hg}$ from the mine soil could be completely removed at 500 and $700{ }^{\circ} \mathrm{C}$, respectively. The desorption efficiency of the industrial soil under the same conditions was only $86.7 \%$ and $89.1 \%$, respectively. Considering that the organic matter content of the industrial soil is higher than that of the mine soil, a possible explanation for this result is that more energy is required to remove $\mathrm{Hg}$ from industrial soil (Falciglia et al. 2011; Lee et al. 2020). Despite a relatively higher concentration of $\mathrm{Hg}$ in the mine soil, $\mathrm{Hg}$ desorption efficiency was greater than that in the industrial soil. These results are consistent with the results of the TOC concentrations and weight loss of the treated soil at different temperatures in Fig. 2b. The TOC concentrations of the treated soil at $100-300{ }^{\circ} \mathrm{C}$ were higher than that of untreated soil, which is mainly due to the break-up of organic carbon, while the TOC concentration was reduced as the temperature increased from 300 to $700{ }^{\circ} \mathrm{C}$. These findings suggest that soil organic carbon contributes to an increase in the gas phase of $\mathrm{Hg}$. Weight loss was also affected by organic matter content (up to $\sim 500{ }^{\circ} \mathrm{C}$ ).

A six-step sequential extraction was conducted to assess the relative lability in the untreated original soils (Fig. 3). Neither soil released Hg in fractions 1 and 2. This result implies that the original soils were less mobile in the environment. The Hg in the industrial soil was bound to amorphous oxide-bound (step 3,14.2\%), crystalline oxide-bound (step 4, $24.2 \%$ ), non-labile organic and elemental (step 5, 29.5\%), and sulfide-bound and residual (step 6,32.1\%), which indicates that each step reflects the presence of various $\mathrm{Hg}$ compounds in the soil (Biester and Nehrke 1997; Tong et al. 2011). Meanwhile, the $\mathrm{Hg}$ in mine soil was primarily associated with the sulfide-bound and residual (step 6, 97.8\%). In general, the mobility of $\mathrm{Hg}$ in soil decreased as the sequential extraction to the later fractions. It can be seen that $\mathrm{Hg}$ in the industrial soil was weakly bound to soil and more labile compared to $\mathrm{Hg}$ in

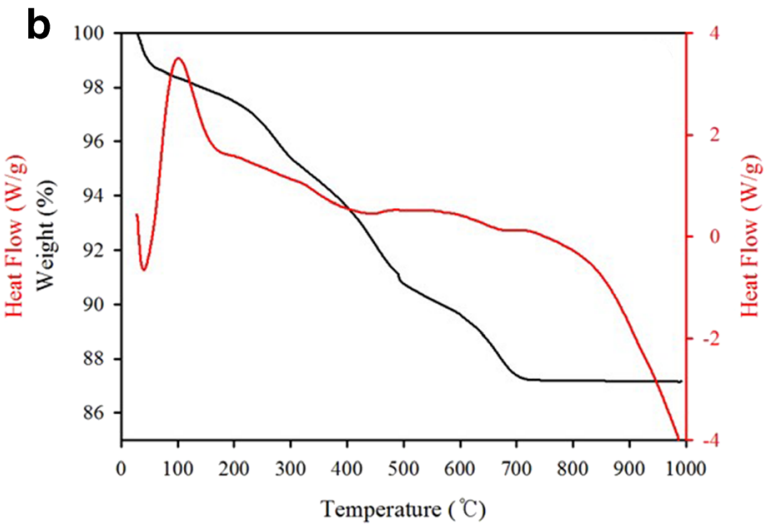



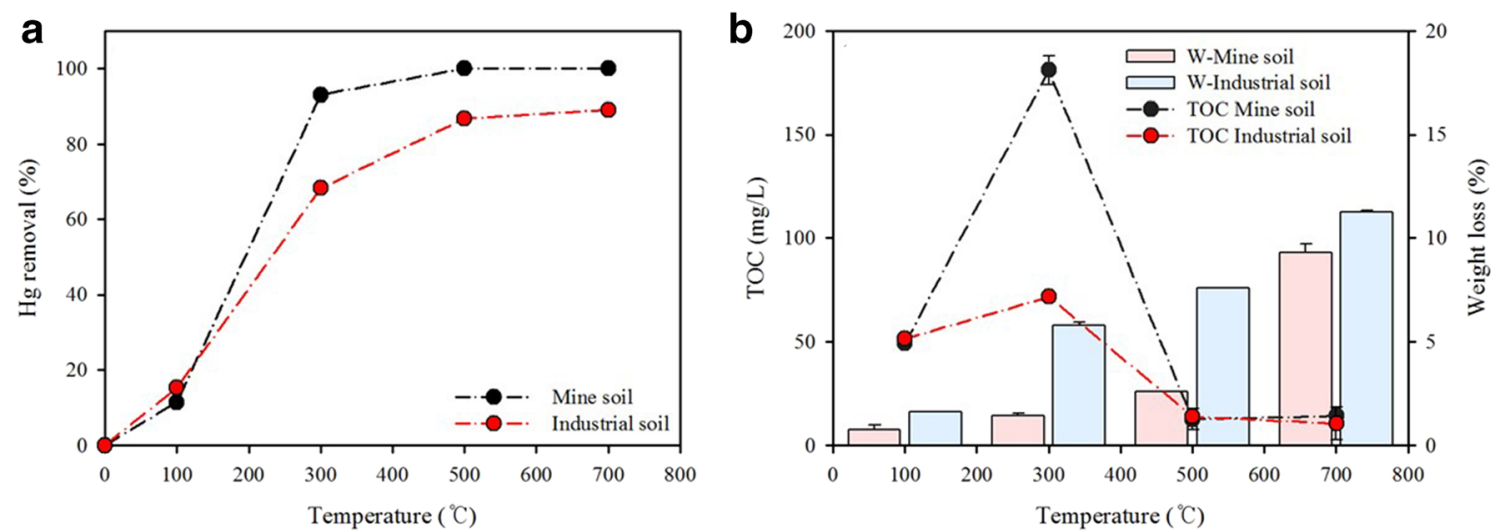

Fig. 2 a Hg removal from soil samples at different temperatures; b TOC concentrations (TOC) and weight loss (W) of soil samples treated at different temperatures

the mine. Sequential extraction was also subjected to thermally treated soil. After both soils were thermally treated at 100 ${ }^{\circ} \mathrm{C}$ for $30 \mathrm{~min}$, the sequential extraction trend was similar to that of the untreated soils. Although $\mathrm{Hg}$ residual fractions (step 6) in the industrial soil were not removed, the Hg residual fractions (step 6) of the mine soil were reduced to $8.40 \%$. This finding indicates that the change in $\mathrm{Hg}$ residual fractions (step 6) at $100^{\circ} \mathrm{C}$ is associated with the form of soil properties. It can be seen that organic carbon was holding $\mathrm{Hg}$ in a more labile form, whereas functional groups of organic matter were associated with immobile fractions with tighter binding. This indicates that the high $\mathrm{Hg}$-binding capacity depends on soil organic matter content. After treatment at $300{ }^{\circ} \mathrm{C}$ for $30 \mathrm{~min}$, the concentration of $\mathrm{Hg}$ residual fractions (step 6) extract was $61.5 \mathrm{mg} / \mathrm{kg}$ with a removal rate of $93.8 \%$. It was found that the removal efficiency increased as the temperature rose, and the desorption efficiency of mine soil at $300{ }^{\circ} \mathrm{C}$ was higher than that of industrial soil. It can be seen that the difference in removal efficiency at $300{ }^{\circ} \mathrm{C}$ may be related to the change in mineralogical properties. Meanwhile, the various $\mathrm{Hg}$ species in the soil could not be distinguished by sequential extraction. $\mathrm{Hg}$ adsorbed to organic matter is simultaneously associated

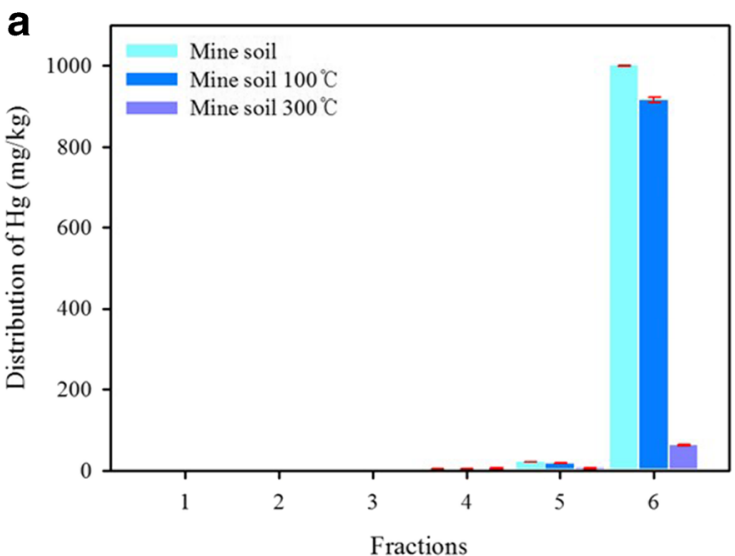

with different forms and is therefore difficult to separate (Biester and Scholz 1996; Kim et al. 2000; Sysalova et al. 2017). It can be seen that the sequential extraction proposed by Hall and Pelchat (2005) is limited to determining Hg species and influenced by the amount of carbonates and soil organic matter.

\section{Characterization of $\mathrm{Hg}$-contaminated soil at different temperatures}

To study the soil minerals' changes during thermal treatment, XRD analyses were conducted to confirm the changes (Fig. 4). By comparing the patterns of untreated and treated samples, no significant changes were observed in the treated soil. However, the intensity of the dolomite peaks decreased in the mine soil, indicating that carbonate components with $\mathrm{Hg}$ in the soil may be removed from the soil into the gas phase. It can be seen that partial decomposition of dolomite in the soil was considered for the displacement of the gas phase of $\mathrm{Hg}$. An XRD analysis was conducted for the residual soils after sequential extraction (Fig. S2). The XRD peak of the industrial soil did not show any distinct change from the XRD pattern of

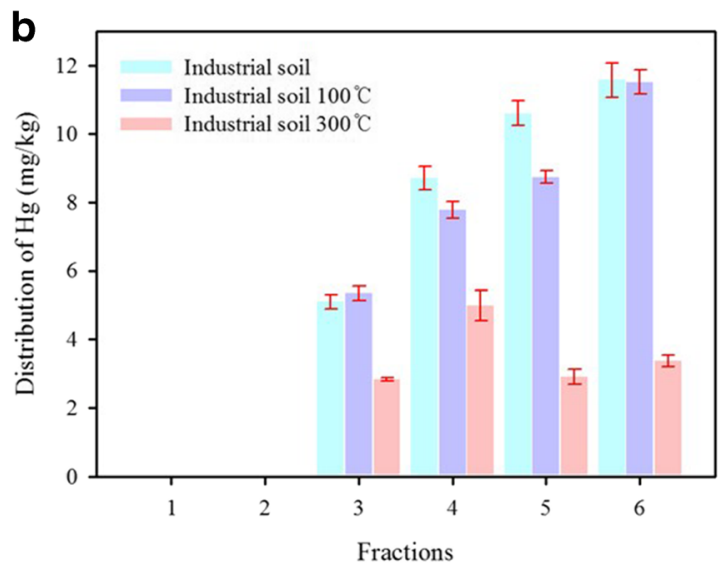

Fig. 3 Sequentially extracted fractions of $\mathrm{Hg}$ from $\mathrm{Hg}$-contaminated soil samples before and after thermal treatment at 100 and $300{ }^{\circ} \mathrm{C}$, for $30 \mathrm{~min}(\mathbf{a}$ mine soil and $\mathbf{b}$ industrial soil) 
Fig. 4 X-ray diffraction patterns of Hg-contaminated soil samples before and after thermal treatment at 300 and $700{ }^{\circ} \mathrm{C}$, for $30 \mathrm{~min}(\mathbf{a}$ mine soil and $\mathbf{b}$ industrial soil $)(C$, calcite; D, dolomite; $\mathrm{M}$, muscovite; $\mathrm{Q}$, quartz)

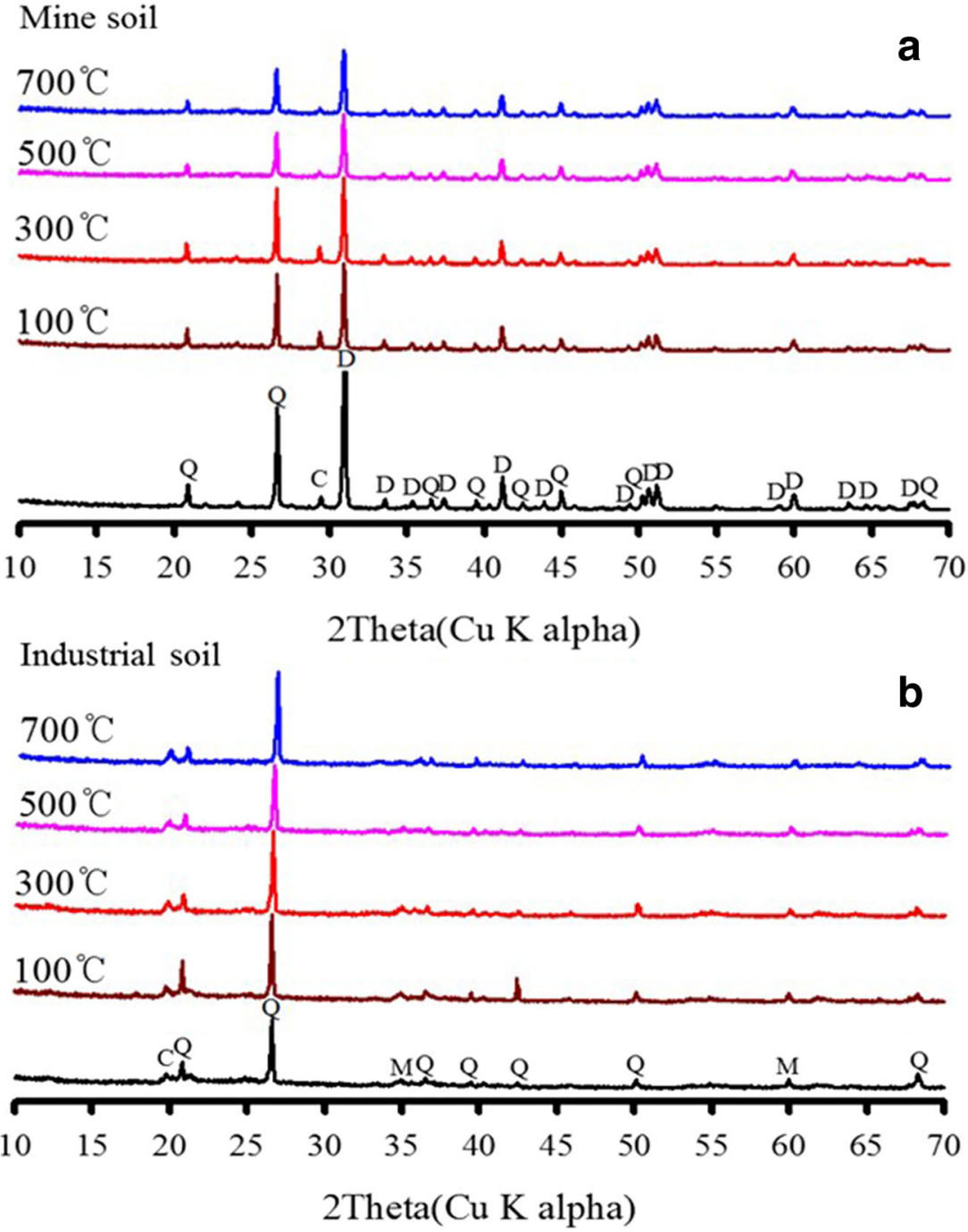

the untreated original soil. However, the dolomite peak in the mine soil decreased and disappeared as the sequential extraction proceeded to the later fractions; only quartz was observed in the residual fractions. It was found that correlations between dolomite and $\mathrm{Hg}$ were observed, which indicates that the dolomite influenced $\mathrm{Hg}$ removal in the soil.

The thermal decomposition of soil components during thermal treatment was further explored, and the results of the functional groups of the heating conditions detected by FTIR spectroscopy are shown in Fig. 5. Hg binds to organic matter colloids because of its high specific surface area and the presence of surface functional groups (Yang and Ok 2017; O'Connor et al. 2019). Both soils showed characteristics of organic matter functional groups such as hydroxyl and carboxyl. The broad bands in the $3400-3300 \mathrm{~cm}^{-1}$ region, the band near 3700 and $3620 \mathrm{~cm}^{-1}$, and the peaks at 913 and 536 $\mathrm{cm}^{-1}$ are attributed to the vibration of hydroxyl groups (Huang et al. 2019). In addition, peaks at 1820,1630 , and $1440 \mathrm{~cm}^{-1}$ correspond to the characteristics of carboxyl groups (Wang et al. 2019). In industrial soil, peaks at 1033, 912, 797, 694, and $471 \mathrm{~cm}^{-1}$ are dominated by $\mathrm{Si}-\mathrm{O}$ stretching vibration bands of quartz (Kim et al. 2015). Furthermore, the carbonates in the mine soil were demonstrated by the absorption bands between 3020 and $2916 \mathrm{~cm}^{-1}, 2627$ and $2523 \mathrm{~cm}^{-1}$, and 1084 and $1031 \mathrm{~cm}^{-1}$ (Ji et al. 2009).

When the temperature rose to 300 and $700{ }^{\circ} \mathrm{C}$, the interaction between $\mathrm{Hg}$ and soils was investigated and compared with the FTIR results of the soil. With increasing temperature, the stretching vibration absorptions of carbonate species weakened gradually in the mine soil. This could be explained by the decomposition of carbonates. Therefore, it seems that the soil sample has a considerable amount of dolomite, which undergoes various thermal reactions such as oxidation and decomposition during thermal treatment. At the same time, the surface of particles became more porous along with the release of the $\mathrm{CO}_{2}$ (Reactions 3 and 4). This implies that the $\mathrm{Hg}$ in the sample may have been removed to the matrix mineral surfaces, or to organic matter. Meanwhile, in the industrial soil, hydroxyl compounds at 3697 and $3620 \mathrm{~cm}^{-1}$ decrease due to the interaction of functional groups of organic ligands 
Fig. 5 FTIR spectra of Hgcontaminated soil samples before and after thermal treatment at 300 and $700{ }^{\circ} \mathrm{C}$, for $30 \mathrm{~min}$ (a mine soil and $\mathbf{b}$ industrial soil)

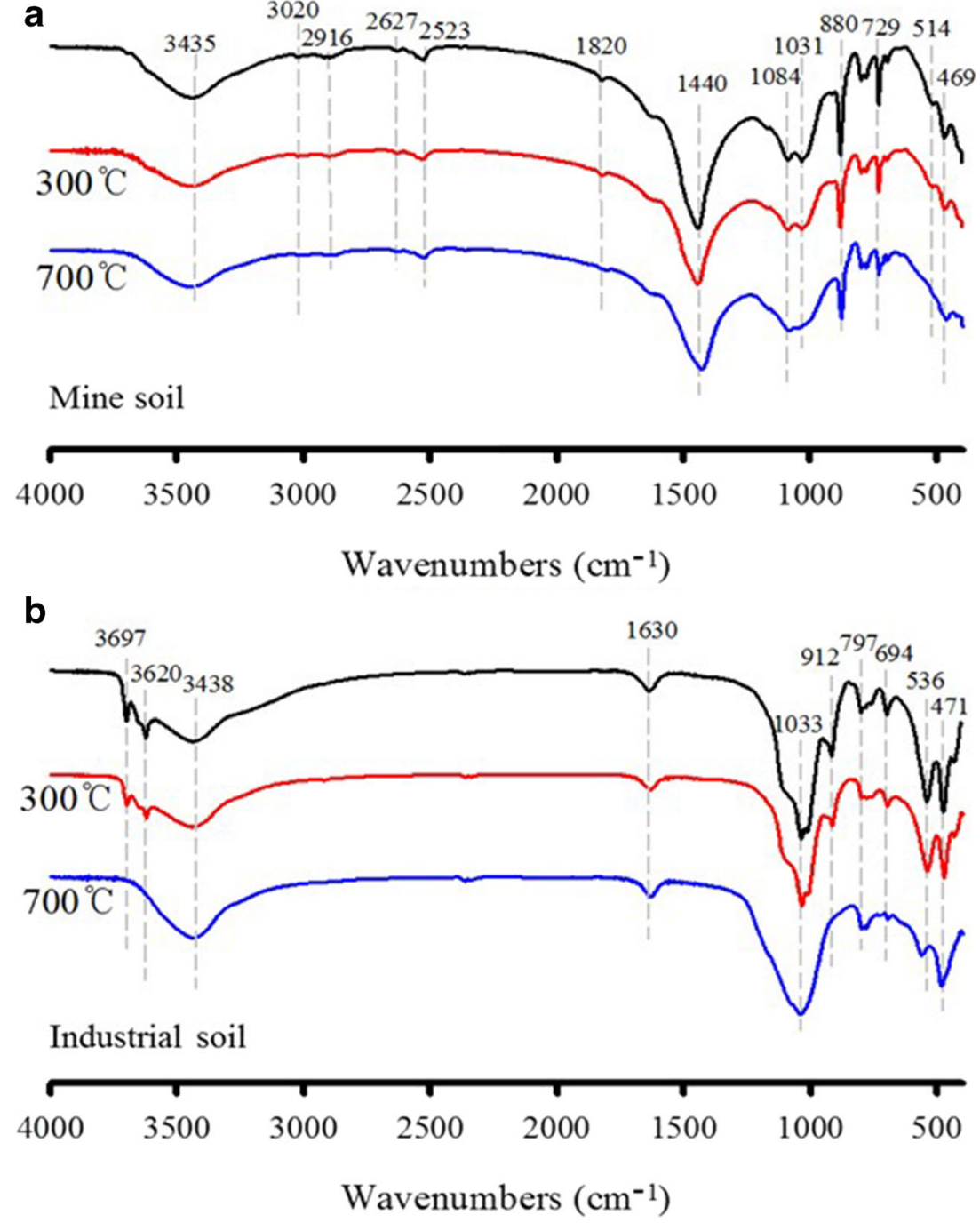

with $\mathrm{Hg}$. The bands at 3438 and $1630 \mathrm{~cm}^{-1}$ in the industrial soil were the most prominent, but these bands did not show any distinct change. The two soils show the interaction of $\mathrm{Hg}$ with hydroxyl groups and between $\mathrm{Hg}$ and carboxylate functional groups. These peaks still appear but in a weakened form at $300{ }^{\circ} \mathrm{C}$, and almost completely disappear at $700{ }^{\circ} \mathrm{C}$. Therefore, it seems that a high removal of $\mathrm{Hg}$ in the soil could be achieved by thermal desorption.

Moreover, changes in various functional groups of the residual soils after sequential extraction for each fraction were evaluated (Fig. S3). Compared with residual soil from mine soil for each fraction, new peaks at 3695 and $3619 \mathrm{~cm}^{-1}$ arise in the FTIR curve of step 3 and step 4 residual soil, which are attributed to the hydroxyl groups. Notably, the hydroxyl groups were observed in different steps at 100 and $300{ }^{\circ} \mathrm{C}$, which may be related to the thermal desorption behavior. It can be seen that $\mathrm{Hg}$ compounds in the mine soil have no tendency to react with weak acids or bases and are immobile on the solid matrix. This result provides evidence that $\mathrm{Hg}$ binding depends on soil characteristics such as inorganic carbonate minerals. In contrast to mine soil, $\mathrm{Hg}$ retention capacity in industrial soil may be due to binding with organic matter, which has covalent bonds. It indicates that the strong binding of $\mathrm{Hg}$ in soils is due to stable complex formation. $\mathrm{Hg}$ in soil tends to be involved in covalent bonds with the $\mathrm{O}$ atoms of organic matter functional groups (e.g., $-\mathrm{OH}, \mathrm{O}-\mathrm{C}=\mathrm{O}$, and $\mathrm{C}=\mathrm{O}$ ), implying that organo- $\mathrm{Hg}$ compounds were stronger than carbon compounds, such as carbonates (Soares et al. 2015; Wang et al. 2019).

\section{Removal kinetics of $\mathrm{Hg}$ under thermal treatment}

The Hg removal efficiencies of the two soil samples were investigated at 100 and $300{ }^{\circ} \mathrm{C}$ (Fig. 6a-b). At each temperature, the removal efficiency increased with reaction time. The residual $\mathrm{Hg}$ concentrations at different temperatures were fitted via an exponential decay kinetic model (Eq. 2), and the kinetic parameters are shown in Table S2. The $K$ value 

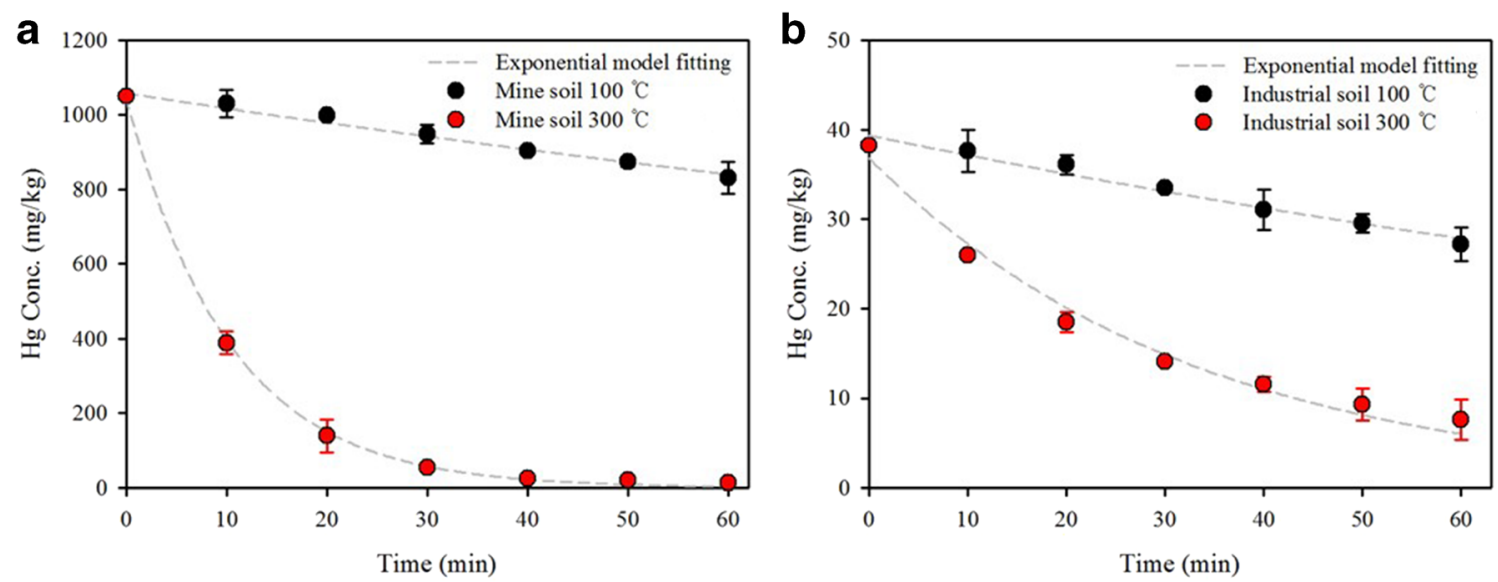

Fig. $6 \mathrm{Hg}$ removal efficiency at 100 and $300{ }^{\circ} \mathrm{C}$ within $60 \mathrm{~min}$ of a mine soil and $\mathbf{b}$ industrial soil

increased with increasing temperature for soils due to the nature of the thermal process, and the $K$ value of the mine soil was higher than that of the industrial soil. No significant difference in either soil type was observed at $100{ }^{\circ} \mathrm{C}$, but a difference in removal efficiency was observed at $300{ }^{\circ} \mathrm{C}$. This indicates that the decay rate is correlated with the characteristics of the soil. As shown in Table 1 , more $\mathrm{CaO}$ was present in the mine soil than in the industrial soil. This difference in chemical composition in the soil seemed to affect $\mathrm{Hg}$ removal. The main reason for this may be the partial decomposition of carbonate minerals in the mine soil at $300{ }^{\circ} \mathrm{C}$, caused by the diffusion of the $\mathrm{CO}_{2}$ released from the reaction surface and heat transfer inside the particle. The SEM image clearly shows that the surface of the soil grains yields a much more porous structure due to the diffusion of $\mathrm{CO}_{2}$, resulting in the partial decomposition reaction (Fig. S4). Zarghami et al. (2015) reported the effect of steam on the partial decomposition of dolomite. Steam improves the connectivity of the pores inside the dolomite particles, which decreases the diffusion resistance of carbon dioxide produced inside the particle. The $\mathrm{Hg}$ was bound to the soil component, either by outer-sphere complexes or by inner-sphere complexes (Reis et al. 2016). The adsorbed $\mathrm{Hg}$ in inner-sphere sorption sites of soil needed a relatively higher desorption temperature due to a diffusion process (Falciglia et al. 2011; Park et al. 2020). The pores inside the soil particles of mine soil could increase the heat transfer ability and effective diffusivity. The $\mathrm{Hg}$ removal efficiency through this porous layer plays a key role in the mine soil.

Soil $\mathrm{pH}$ analysis was conducted for the thermal-treated soil. The mine soil showed near-neutral $\mathrm{pH}$ when treated at $100^{\circ} \mathrm{C}$, while that treated at $300^{\circ} \mathrm{C}$ resulted in a basic $\mathrm{pH}$. Meanwhile, the $\mathrm{pH}$ of the industrial soil was always lower than the $\mathrm{pH}$ of the mine soil. The two different soil $\mathrm{pH}$ values may be explained by, compared with organic matter content, and soil minerals such as dolomite and calcite. The mine soil, which could be related to the degradation of the organic mattercarbonate complexes, which is in correlation with high $\mathrm{Ca}$ content, seems to decrease with increasing soil $\mathrm{pH}$. Industrial soil's pH was slightly increased in terms of the time at different temperatures, which is caused by the loss of organic acids such as fulvic and humic acids (Ravichandran et al. 1999; Xu et al. 2014). Therefore, soil $\mathrm{pH}$ changes during thermal desorption are influenced by heating time and temperature.

\section{Discussion}

Based on the analysis above, $\mathrm{Hg}$ tends to be immobilized in the soil due to its affinity for mineral surfaces and bonding to organic matter. In this study, the soil composition played an important role in $\mathrm{Hg}$ removal. The thermal desorption-related $\mathrm{Hg}$ bonding strength of soils can be largely attributed to the interactions between $\mathrm{Hg}$ and soil, which involve sorption to soil organic matter and soil matrices, and the influence of soil properties on $\mathrm{Hg}$ speciation (Lesa et al. 2009; Park et al. 2015). However, the precise species could not be distinguished by this study. The $\mathrm{Hg}$ phase transition reactions and decomposition of $\mathrm{Hg}$ solid in standard enthalpy showed that $\mathrm{Hg}$ could be converted to the gas phase by thermal treatment (Table S3). The positive values of enthalpy change $\left(\Delta \mathrm{H}^{\circ}\right)$ indicate that the $\mathrm{Hg}$ desorption reactions are endothermic, which indicates that the higher temperature contributes to the effective $\mathrm{Hg}$ removal from contaminated soil. In general, $\mathrm{Hg}$ compounds such as $\mathrm{HgO}$ and $\mathrm{HgS}$ are insoluble and much less volatile than other forms of $\mathrm{Hg}$; therefore, they require larger increases in temperature to achieve $\mathrm{Hg}$ removal. It seems that thermal desorption would be affected by different $\mathrm{Hg}$ species, which was attributed to the presence of surface functional groups such as $\mathrm{O}-, \mathrm{N}$-, and $\mathrm{S}$-containing ligands (Powell et al. 2004). Hence, it is noted that organic matter content may be regarded as an important interaction during thermal treatment. The diffusion barrier of $\mathrm{Hg}$ release is affected by soil matrix components, and the higher organic 
matter in the soil controlled the desorption process, resulting in an increase in the diffusion barrier of $\mathrm{Hg}$ release. Moreover, for carbonate, the presence of organic carbon made it possible to evaporate $\mathrm{Hg}$ rapidly, which could be related to the steam stripping and morphology effect.

Overall, the soil composition for thermal desorption might strongly influence the desorption of $\mathrm{Hg}$ from the soil. It can be seen that the vaporization of $\mathrm{Hg}$ occurred because of soil components such as moisture and organic matter, which indicates that $\mathrm{Hg}$ thermal desorption could be ascribed to stripping by water distillation and gasification through organic matter cracking and partial decomposition of inorganic carbonate. The effect of soil composition on $\mathrm{Hg}$ desorption showed that the behavior at $100{ }^{\circ} \mathrm{C}$ was similar, but a different behavior could be found at 300 ${ }^{\circ} \mathrm{C}$. Hg desorption during the thermal treatment at $100{ }^{\circ} \mathrm{C}$ occurred from the soil particle surface and was caused by the effect of water stripping. Meanwhile, at $300{ }^{\circ} \mathrm{C}, \mathrm{Hg}$ desorption is affected by the saturated vapor pressure of soil substances and the creation of permeability, thus contributing to a higher Hg removal due to the partial decomposition of carbonate in the soil composition.

\section{Conclusions}

This study showed that thermal treatment of $\mathrm{Hg}$ contaminated soil with different soil properties could result in different $\mathrm{Hg}$ desorption efficiencies. The thermal desorption efficiency in soils at different temperatures is affected by the thermal properties of soils and the Hg desorption capacity of the soils. Since organic matter forms covalent bonds with organic matter functional groups such as hydroxyl and carboxyl, the desorption process is controlled by diffusion barriers such as interactions between $\mathrm{Hg}$ and soil. Overall, the soil properties have an essential effect on the desorption process. The thermal desorption mechanism is strongly influenced by the vapor pressure and the morphological changes in the soils. As the temperature increased, the TOC concentration increased at $100-300{ }^{\circ} \mathrm{C}$, and then decreased above $300{ }^{\circ} \mathrm{C}$. Weight loss was also found to be affected by organic matter content. No significant difference in either soil type was observed at $100{ }^{\circ} \mathrm{C}$, but a difference in desorption efficiency was observed at $300{ }^{\circ} \mathrm{C}$. The results of $\mathrm{Hg}$ desorption kinetics show that the desorption process was controlled by soil properties, which may be related to the soil $\mathrm{Hg}$ desorption capacity. The volatilization of $\mathrm{Hg}$ in the soil is induced by organic carbon, while soil $\mathrm{Hg}$ release is controlled by organic matter complexes. Therefore, understanding the effects of the desorption process on soil properties may be considered an effective approach to improving $\mathrm{Hg}$ desorption efficiency.
Supplementary Information The online version contains supplementary material available at https://doi.org/10.1007/s11356-021-14024-z.

Author contribution Conceptualization, S.-B.K.; methodology, O.P. and E.-J.M.; validation, N.-C.C.; investigation, H.-S.K.; funding acquisition, N.-C.C.; project administration, N.-C.C.; writing — original draft, K.-H.C. and J.-K.K.; writing - review \& editing, K.-H.C. All authors have read and agreed to the published version of the manuscript.

Funding This subject is supported by the Korea Ministry of Environment as "Prospective green technology innovation project (2020003160015)."

Data availability All data generated or analyzed during this study are included in this published article (and its supplementary information files).

\section{Declarations}

Ethics approval and consent to participate Not applicable.

Consent for publication Not applicable.

Competing interests The authors declare no competing interests.

Open Access This article is licensed under a Creative Commons Attribution 4.0 International License, which permits use, sharing, adaptation, distribution and reproduction in any medium or format, as long as you give appropriate credit to the original author(s) and the source, provide a link to the Creative Commons licence, and indicate if changes were made. The images or other third party material in this article are included in the article's Creative Commons licence, unless indicated otherwise in a credit line to the material. If material is not included in the article's Creative Commons licence and your intended use is not permitted by statutory regulation or exceeds the permitted use, you will need to obtain permission directly from the copyright holder. To view a copy of this licence, visit http://creativecommons.org/licenses/by/4.0/.

\section{References}

Biester H, Nehrke G (1997) Quantification of mercury in soils and sediments-acid digestion versus pyrolysis. Fresenius J Anal Chem 358:446-452

Biester H, Scholz C (1996) Determination of mercury binding forms in contaminated soils: mercury pyrolysis versus sequential extractions. Environ Sci Technol 31:233-239

Cho K, Myung E, Kim H, Purev O, Park C, Choi N (2020) Removal of total petroleum hydrocarbons from contaminated soil through microwave irradiation. Int J Environ Res Public Health 17

Falciglia PP, Giustra MG, Vagliasindi FG (2011) Low-temperature thermal desorption of diesel polluted soil: influence of temperature and soil texture on contaminant removal kinetics. J Hazard Mater 185: $392-400$

Feng X, Qiu G (2008) Mercury pollution in Guizhou, Southwestern China - an overview. Sci Total Environ 400:227-237

Guo S, Niu X, Zhai J (2017) Mercury release during thermal treatment of two Chinese coal gangues. Environ Sci Pollut Res 24:23578-23583

Hall GE, Pelchat P (2005) The design and application of sequential extractions for mercury, part 2. Resorption of mercury onto the sample during leaching. Geochemistry: Exploration, environment, analysis 5:115-121 
Heiri O, Lotter AF, Lemcke G (2001) Loss on ignition as a method for estimating organic and carbonate content in sediments: reproducibility and comparability of results. J Paleolimnol 25:101-110

Huang Y, Wang M, Li Z, Gong Y, Zeng EY (2019) In situ remediation of mercury-contaminated soil using thiol-functionalized graphene oxide/Fe-Mn composite. J Hazard Mater 373:783-790

Jho EH, Im J, Yang K, Kim YJ, Nam K (2015) Changes in soil toxicity by phosphate-aided soil washing: effect of soil characteristics, chemical forms of arsenic, and cations in washing solutions. Chemosphere 119:1399-1405

Ji J, Ge Y, Balsam W, Damuth JE, Chen J (2009) Rapid identification of dolomite using a Fourier transform infrared spectrophotometer (FTIR): a fast method for identifying Heinrich events in IODP Site U1308. Mar Geol 258:60-68

Kim EJ, Baek K (2015) Enhanced reductive extraction of arsenic from contaminated soils by a combination of dithionite and oxalate. $\mathrm{J}$ Hazard Mater 284:19-26

Kim CS, Brown GE Jr, Rytuba JJ (2000) Characterization and speciation of mercury-bearing mine wastes using X-ray absorption spectroscopy. Sci Total Environ 261:157-168

Lee WR, Eom Y, Lee TG (2017) Mercury recovery from mercurycontaining wastes using a vacuum thermal desorption system. Waste Manag 60:546-551

Lee ES, Cho SJ, Back SK, Seo YC, Kim SH, Ko JI (2020) Effect of substitution reaction with tin chloride in thermal treatment of mercury contaminated tailings. Environ Pollut 264:114761

Lesa B, Aneggi E, Rossi G, Comuzzi C, Goi D (2009) Bench-scale tests on ultrasound-assisted acid washing and thermal desorption of mercury from dredging sludge and other solid matrices. J Hazard Mater 171:647-653

Li M, Drosos M, Hu H, He X, Wang G, Zhang H, Hu Z, Xi B (2019) Organic amendments affect dissolved organic matter composition and mercury dissolution in pore waters of mercury-polluted paddy soil. Chemosphere 232:356-365

Li F, Zhang Y, Wang S, Chen C, Shen K (2020) Insight into ex-situ thermal desorption of soils contaminated with petroleum via carbon number-based fraction approach. Chem Eng J 385:123946

Liu H, Li J, Zhao M, Li Y, Chen Y (2019) Remediation of oil-based drill cuttings using low-temperature thermal desorption: performance and kinetics modeling. Chemosphere 235:1081-1088

Ma F, Zhang Q, Xu D, Hou D, Li F, Gu Q (2014) Mercury removal from contaminated soil by thermal treatment with $\mathrm{FeCl}(3)$ at reduced temperature. Chemosphere 117:388-393

O'Connor D, Hou D, Ok YS, Mulder J, Duan L, Wu Q, Wang S, FMG T, Rinklebe J (2019) Mercury speciation, transformation, and transportation in soils, atmospheric flux, and implications for risk management: a critical review. Environ Int 126:747-761

O'Brien PL, DeSutter TM, Casey FXM, Khan E, Wick AF (2018) Thermal remediation alters soil properties - a review. J Environ Manag 206:826-835

Park CM, Katz LE, Liljestrand HM (2015) Mercury speciation during in situ thermal desorption in soil. J Hazard Mater 300:624-632

Park M-o, Kim M-H, Hong Y (2020) The kinetics of mercury vaporization in soil during low-temperature thermal treatment. Geoderma 363

Powell KJ, Brown PL, Byrne RH, Gajda T, Hefter G, Sjöberg S, Wanner $\mathrm{H}$ (2004) Chemical speciation of $\mathrm{Hg}$ (II) with environmental inorganic ligands. Aust J Chem 57:993-1000

Qian H, Kai W, Hongde X (2019) A novel perspective of dolomite decomposition: elementary reactions analysis by thermogravimetric mass spectrometry. Thermochim Acta 676:47-51

Ravichandran M, Aiken GR, Ryan JN, Reddy MM (1999) Inhibition of precipitation and aggregation of metacinnabar (mercuric sulfide) by dissolved organic matter isolated from the Florida Everglades. Environ Sci Technol 33:1418-1423
Reis AT, Coelho JP, Rucandio I, Davidson CM, Duarte AC, Pereira E (2015) Thermo-desorption: a valid tool for mercury speciation in soils and sediments? Geoderma 237-238:98-104

Reis AT, Davidson CM, Vale C, Pereira E (2016) Overview and challenges of mercury fractionation and speciation in soils. TrAC Trends Anal Chem 82:109-117

Riccardi D, Guo HB, Parks JM, Gu BH, Summers AO, Miller SM, Liang LY, Smith JC (2013) Why mercury prefers soft ligands. The Journal of Physical Chemistry Letters 4:2317-2322

Rumayor M, Diaz-Somoano M, Lopez-Anton MA, Martinez-Tarazona MR (2013) Mercury compounds characterization by thermal desorption. Talanta 114:318-322

Soares LC, Egreja Filho FB, Linhares LA, Windmoller CC, Yoshida MI (2015) Accumulation and oxidation of elemental mercury in tropical soils. Chemosphere 134:181-191

Soucémarianadin L, Cécillon L, Chenu C, Baudin F, Nicolas M, Girardin C, Delahaie A, Barré P (2019) Heterogeneity of the chemical composition and thermal stability of particulate organic matter in French forest soils. Geoderma 342:65-74

Stevenson FJ (1994) Humus chemistry: genesis, composition, reactions. John Wiley \& Sons

Sysalova J, Kucera J, Drtinova B, Cervenka R, Zverina O, Komarek J, Kamenik J (2017) Mercury species in formerly contaminated soils and released soil gases. Sci Total Environ 584-585:1032-1039

Tian Y, Li J, Yan X, Whitcombe T, Thring R (2019) Co-pyrolysis of metal contaminated oily waste for oil recovery and heavy metal immobilization. J Hazard Mater 373:1-10

Tomiyasu T, Kodamatani H, Imura R, Matsuyama A, Miyamoto J, AkagiH KD, Kotnik J, Fajon V, Horvat M (2017) The dynamics of mercury near Idrija mercury mine, Slovenia: horizontal and vertical distributions of total, methyl, and ethyl mercury concentrations in soils. Chemosphere 184:244-252

Tong S, Fan M, Mao L, Jia CQ (2011) Sequential extraction study of stability of adsorbed mercury in chemically modified activated carbons. Environ Sci Technol 45:7416-7421

Valverde JM, Perejon A, Medina S, Perez-Maqueda LA (2015) Thermal decomposition of dolomite under $\mathrm{CO}_{2}$ : insights from TGA and in situ XRD analysis. Phys Chem Chem Phys 17:30162-30176

Vasques ICF, Egreja Filho FB, Morais EG, Lima FRD, Oliveira JR, Pereira P, Guilherme LRG, Marques JJ (2020) Mercury fractionation in tropical soils: a critical point of view. Chemosphere 257:127114

Wang J, Feng X, Anderson CW, Xing Y, Shang L (2012) Remediation of mercury contaminated sites - a review. J Hazard Mater 221-222:1-18

Wang X, Wang S, Pan X, Gadd GM (2019) Heteroaggregation of soil particulate organic matter and biogenic selenium nanoparticles for remediation of elemental mercury contamination. Chemosphere 221:486-492

Xu J, Kleja DB, Biester H, Lagerkvist A, Kumpiene J (2014) Influence of particle size distribution, organic carbon, $\mathrm{pH}$ and chlorides on washing of mercury contaminated soil. Chemosphere 109:99-105

Yang JE, Ok YS (2017) Kinetics of Hg adsorption onto noncrystalline Al hydroxide as influenced by low-molecular-weight organic ligands. Arch Agron Soil Sci 63:124-135

Zarghami S, Ghadirian E, Arastoopour H, Abbasian J (2015) Effect of steam on partial decomposition of dolomite. Ind Eng Chem Res 54: $5398-5406$

Zhao H, Yan H, Zhang L, Sun G, Li P, Feng X (2019) Mercury contents in rice and potential health risks across. China Environ Int 126:406-412

Publisher's note Springer Nature remains neutral with regard to jurisdictional claims in published maps and institutional affiliations. 